\title{
Intrabiliary Route of Administration
}

National Cancer Institute

\section{Source}

National Cancer Institute. Intrabiliary Route of Administration. NCI Thesaurus. Code C38224.

Administration within the biliary system for selective delivery of the agent to targeted hepatobiliary tissues and cell types, the goal of which is utilization of optimal therapeutic dosages combined with a reduction in systemic toxicity. Strategies for improving the tissue specificity include the use of tissue-specific ligands and the focal administration of drugs. Focal delivery has been primarily directed at uptake by the hepatocyte basolateral membrane and has included direct intraparenchymal injection, portal venous infusion, hepatic arterial infusion, and surgical systems for temporarily isolating the liver from the vasculature. 